\title{
Possible Sources of Long-Term Variations in the Mid-Latitude Ionosphere
}

\author{
Ana G. Elias ${ }^{*}$ \\ CONICET, Consejo Nacional de Investigaciones Cientificas y Tecnicas, Argentina \\ Universidad Nacional de Tucuman, Facultad de Ciencias Exactas y Tecnologia, Departamento de Fisica, Av. \\ Independencia 1800, 4000 Tucumán, Argentina
}

\begin{abstract}
Trends in the upper atmosphere, together with the global warming of the lower atmosphere, are part of the global change of the Earth system. In the present work, which is focused in the upper atmosphere, long-term variations of the critical frequency of the ionospheric F2 layer, foF2, are studied in terms of the following possible causes: (1) longterm variations of the solar EUV radiation shown by the solar cycle length (SCL), (2) long-term variations in geomagnetic activity measured by the aa index, (3) the increasing greenhouse gases concentration in the lower atmosphere which would be producing a temperature decrease in the upper atmosphere, and (4) the Earth's main magnetic field secular variation, which implies changes in the dip angle (I) affecting the thermospheric neutral winds that move the conducting plasma of the ionosphere. For this purpose, foF2 time series of four mid-latitude stations were processed. After filtering the solar activity effect, the long-term variability of these time series and that of the mentioned possible trend sources, were analyzed. The study of trends in the upper atmosphere is an important contribution to one of the present focus of climate science that is the determination of the extent to which human activities are altering the planetary energy balance through the emission of greenhouse gases and pollutants.
\end{abstract}

Keywords: Long-term trends, ionosphere, foF2, Solar cycle length, geomagnetic activity.

\section{INTRODUCTION}

Long-term changes in ionospheric parameters of timescales longer than the 11 year solar activity cycle were analyzed by many authors that, after filtering the effects of solar activity, found long-term variations, or trends. These trends were attributed to solar EUV radiation changes [1,2], geomagnetic activity variations [3-8], the increase of greenhouse gases concentration [9-14], and/or secular variations of the Earth's main magnetic field [15-19]. A description of these possible trend sources of the ionosphere is given in the following sections of the paper. Then, the data analysis is carried out using annual data of ionospheric F2 layer critical frequency, foF2, at $12 \mathrm{LT}$, together with solar and geomagnetic indices. Seasonal and diurnal variations will not be examined in the present paper. The last section includes the discussion and conclusions, stating the importance of atmosphere trend studies for the climate science.

\section{SOLAR EUV RADIATION LONG-TERM VARIATION}

The dependence of foF2 on solar EUV solar radiation is almost linear. It is well known the direct association of this ionospheric parameter to solar EUV proxies such as, the sunspot number, Rz, or the $10.7 \mathrm{~cm}$ solar flux, F10.7, with minor departures such as the saturation effect and the hysteresis [20-24].

\footnotetext{
*Address correspondence to this author at the Universidad Nacional de Tucuman, Facultad de Ciencias Exactas y Tecnologia, Departamento de Fisica, Av. Independencia 1800, 4000 Tucumán, Argentina; Tel: +54 381 4364093; Fax: +54 381 4364093; E-mails: anagelias@yahoo.com, aelias@herrera.unt.edu.ar
}

Friis-Christensen and Lassen [25] used SCL as a proxy of long-term total solar irradiance variations not shown by $\mathrm{Rz}$ or F10.7. Increasing SCL would correspond to decreasing solar irradiance and decreasing SCL, to increasing solar irradiance.

Adler et al. [1] argued that these variations shown by SCL should also appear in the solar radiation range responsible for ionization in the ionosphere, that is the EUV, so changes in the ionosphere related to SCL should also be seen. They found a close association between SCL and $\mathrm{NmF} 2$ after filtering the solar activity effect through Rz, and infer that SCL may provide also a measure of long-term EUV solar variability, but in this case increasing SCL would correspond to increasing EUV and decreasing SCL, to decreasing EUV. After this result SCL is used here as a proxy EUV trends not shown by common EUV indices (i.e. Rz and F10.7).

$\mathrm{SCL}$ is a parameter of long-term variation which has a periodicity of approximately 88 years that is the periodicity also observed in the magnitude of the maximum sunspot number named the Gleissberg period. The SCL series (see Fig. 1) was obtained from Lassen and Friis-Christensen [26], and is available at http://web.dmi.dk/fsweb/solarterrestrial/ sunclimate/SCL.txt. The assessment of the SCL time series is explained in Thejll and Lassen [27] and is briefly as follows:

SCL is assessed from the list of Rz. The cycle length is measured from minimum to subsequent minimum dates and also from maximum to subsequent maximum dates, resulting two lists of solar cycle duration. These measures are associated to the mid-cycle date. Following the procedure 


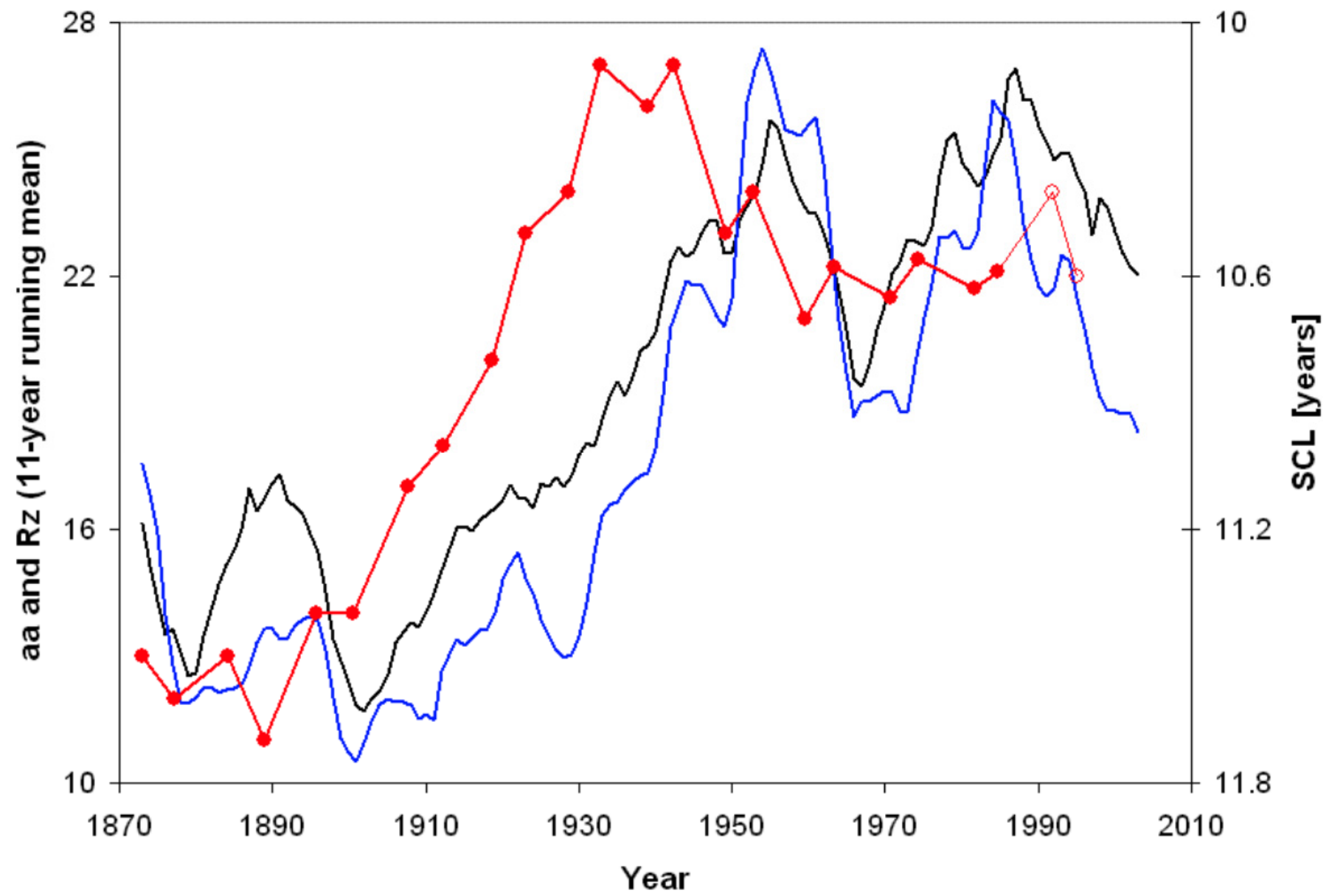

Fig. (1). Solar cycle length (SCL) in years after a 1-2-2-2-1 running mean (red line with solid circle - empty circles correspond to preliminary values), aa geomagnetic index after an 11-year running mean (black line) in nT, and Rz 11-year running mean (blue line) scaled to fit the aa axis.

introduced by Gleissberg [28] a 5-point filter is applied with the consecutive weights $(1 / 8 ; 2 / 8 ; 2 / 8 ; 2 / 8$ and $1 / 8)$ to each list of cycle lengths. This filter is usually referred to as the 12221 filter. Finally, the two lists of weighted cycle lengths are intercalated.

We choose this SCL record since, although different smoothing of SCL give different results, SCL determination by other methods [29-31], is in general good agreement with the record used here.

\section{GEOMAGNETIC ACTIVITY LONG-TERM VARIATION}

During geomagnetic storms a large amount of energy is deposited into the thermosphere at high latitudes. This leads to an increase of the neutral gas temperature and variations of the neutral composition with a decrease of the atom-tomolecule ratio at heights of the $\mathrm{F} 2$ region. Both factors contribute to a decrease of the electron concentration in the high latitude ionosphere [32, 33]. The energy deposition produces also an equatorward circulation. When it coincides with the quiet-time circulation, the gas with depleted atomto-molecule ratio is brought toward low latitudes and so the negative phase extends equatorward. At middle latitudes, the storm-induced circulation increases the plasma upward vertical drift in the F2 layer and so leads to an uplifting of the layer [34, 35]. At lower latitudes, sometimes, the downwelling of the circulation leads to an increase of the atomic oxygen concentration and so to an increase in electron density [35]. It should be expected then that increasing geomagnetic activity would produce an foF2 decrease at high latitudes, with a lesser effect towards lower latitudes, and even a reversal at low latitudes with an foF2 increase final effect.

As a geomagnetic activity index, aa is used in the present work. This is a global geomagnetic activity index which measures the disturbance level of the Earth's magnetic field, and it is derived by two approximately antipodal observatories, originally Greenwich and Melbourne. At present these are Hartland observatory in the UK and Canberra observatory in Australia. The index, in nT units, is available back to 1868 from http://www.wdcb.ru/stp/data/ geomagni.ind/aa/ and also http://isgi.cetp.ipsl.fr/source/indices/.

An 11-year running mean was applied to the annual aa values in order to filter out short-term variations. As can be seen in Fig. (1), and focusing on the period of the ionospheric data here analyzed, geomagnetic activity increased during 1940-1955, followed by a decrease until the end of 1960's, then an increase until the middle 1980's, and has been decreasing since then. The long-term variation of aa is similar to that of $\mathrm{Rz}$, and shifted around 10 years with respect to SCL, as can be seen in Fig. (1). 


\section{INCREASING GREENHOUSE GASES CONCEN- TRATION}

The amount of greenhouse gases in the atmosphere, such as $\mathrm{CO}_{2}$ and $\mathrm{CH}_{4}$, has been increasing during the past few decades $[36,37]$. Current modeling studies indicate that the upper atmosphere may be sensitive to this increase. Brasseur and Hitchman [38] used a two-dimensional numerical model of the stratosphere and found that the net effect of increasing greenhouse gases is a cooling of the entire stratosphere and lower mesosphere, between 20 and $60 \mathrm{~km}$. Roble and Dickinson [39], with a global mean model of the mesosphere, thermosphere and ionosphere between 60 and $500 \mathrm{~km}$, estimate a mesosphere and thermosphere cooling of $10 \mathrm{~K}$ and $50 \mathrm{~K}$ respectively as the $\mathrm{CO}_{2}$ and $\mathrm{CH}_{4}$ mixing ratios are doubled.

Compositional redistribution and ionospheric structure alterations also occur in association with changes in the temperature profile. Theoretical studies examining the consequences of increasing greenhouse gases for the ionosphere, coincide that the F2 layer peak height, $\mathrm{hmF}$ 2, and foF 2 should decrease $[40,41]$. Particularly, the decrease estimated for foF2 [41] is $0.2-0.5 \mathrm{MHz}$ for a doubling of $\mathrm{CO} 2$. Since the greenhouse gases increasing concentration consists of a monotonic upward trend, this hypothesis is checked experimentally estimating, after a proper filtering, the linear trend of the data,

\section{SECULAR VARIATIONS OF THE EARTH'S MAIN MAGNETIC FIELD}

The possibility of ionospheric trends induced by the Earth's magnetic field secular variations was first suggested by Foppiano et al. [15], and followed then by other papers [16-19]. In fact, Earth's magnetic field, generated in the Earth's core, presents long term variations in the field's strength and orientation $[42,43]$.

A simple mechanism through which trends in the Earth's magnetic field may affect the ionosphere is through changes in the dip angle (I) [15]. The $\sin (\mathrm{I}) \cos (\mathrm{I})$ factor, associated with the effects of neutral winds on hmF2 [33, 44, 45] will also change. The horizontal thermospheric wind $U$ drives ions and electrons, up during the night and down during the day, along the geomagnetic field lines at speed $U \cos (I)$. The vertical component $U \sin (\mathrm{I}) \cos (\mathrm{I})$ raises the $\mathrm{F} 2$-peak during night time (when U blows from Pole to Equator) and lowers it during daytime (when $U$ blows from Equator to Pole), increasing or decreasing the peak electron density. An increase in the $\sin (\mathrm{I}) \cos (\mathrm{I})$ factor would produce an additional lowering of the F-region with a decrease in foF2, during daytime, and an additional raise of the region with an increase in foF2 during the night. A decrease in the $\sin (\mathrm{I}) \cos (\mathrm{I})$ factor would produce the opposite effect.

Using simple theoretical considerations, and with the help of empirical models, the expected foF 2 trends were assessed worldwide by Elias and Adler [16] and Elias [17]. The region of strongest variations of foF 2 , lies between $10^{\circ} \mathrm{N}$ and $30^{\circ} \mathrm{S}$ in latitude and between $20^{\circ} \mathrm{E}$ and $80^{\circ} \mathrm{W}$ in longitude, which is also the region of strongest changes in I and $\sin (\mathrm{I}) \cos (\mathrm{I})$ factor. At the mid-latitude zone, corresponding to the locations of the ionospheric stations here analyzed, the expected trends due to changes in I, is not statistically significant different from cero.

\section{DATA ANALYSIS}

The ionospheric parameter foF2 of four mid-latitude stations, listed in Table 1, were analyzed. The data was obtained from the World Data Centre for Solar-Terrestrial Physics at the Rutherford Appleton Laboratory (http://www. wdc.rl.ac.uk).

The solar activity effect was filtered out estimating the foF2 residuals from the regression between the experimental values and solar activity measured through the sunspot number, $\mathrm{Rz}$, that is

foF $2_{\text {res }}=f o F 2_{\exp }-(a R z+b)$

The suffixes exp and res mean experimental and residual respectively. $\mathrm{a}$ and $\mathrm{b}$ are the coefficients of the linear regression between foF 2 exp and Rz. A 5-year running was applied then to the annual foF2 residual series in order to filter out short-term variations, which still persist.

Fig. (2) shows foF $2_{\text {res }}$ together with SCL and aa 11-year running mean. The linear trend of foF $2_{\text {res }}$, also shown in the figure, is $(-0.11 \pm 0.04) \mathrm{MHz} /$ year for Sodankyla, $(-0.06 \pm$ $0.03) \mathrm{MHz} /$ year for Uppsala, and not statistically significant different from cero for Moscow and Ottawa.

The expected foF 2 trend value due to $\mathrm{CO}_{2}$ increase can be estimated by linearly interpolating the value assessed by Rishbeth [40] and Rishbeth and Roble [41] for a doubling of $\mathrm{CO}_{2}$. For a $\sim 20 \%$ increase in $\mathrm{CO}_{2}$, which occurs for the period here analyzed, the theoretical decrease of foF 2 due to greenhouse effect results then $0.001-0.003 \mathrm{MHz} /$ year. To obtain values of this order with statistical significance, longer time series than those now available are needed. However, two of the four stations, Sodankyla and Uppsala, present foF2 significant decreasing trends but much stronger than those expected from the greenhouse gases effect.

Table 1. Geographic and Geomagnetic Coordinates of the Studied Ionospheric Stations, and Available Period of foF2 Data

\begin{tabular}{|c|c|c|c|c|c|}
\hline \multirow{2}{*}{ Station } & \multicolumn{2}{|c|}{ Geographic } & \multicolumn{2}{|c|}{ Geomagnetic } & \multirow{2}{*}{ Period of Data } \\
\cline { 2 - 6 } & Latitude (N) & Longitude (E) & Latitude (N) & 120.8 & $1958-89$ \\
\hline \hline Sodankyla & 67.4 & 26.0 & 63.6 & 106.9 & $1957-98$ \\
\hline Uppsala & 59.8 & 17.6 & 58.3 & 123.2 & $1957-98$ \\
\hline Moscow & 55.5 & 37.3 & 50.4 & 352.7 & $1957-95$ \\
\hline Ottawa & 45.4 & 284.1 & 56.4 & & \\
\hline
\end{tabular}


(a)

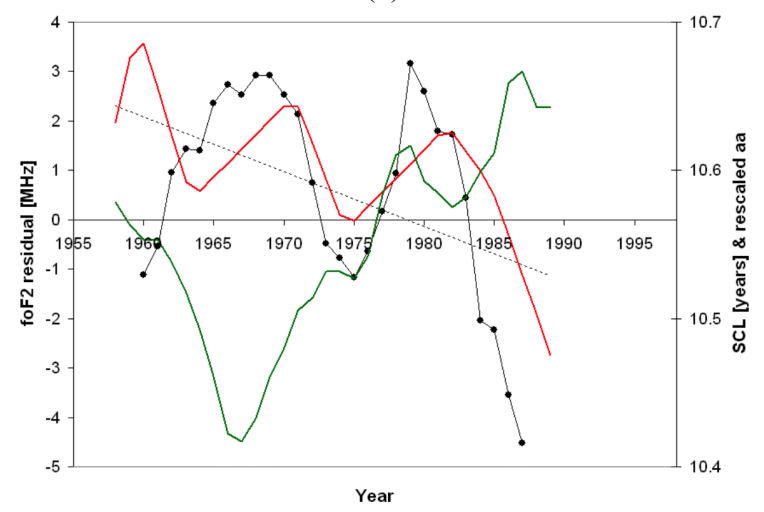

(b)

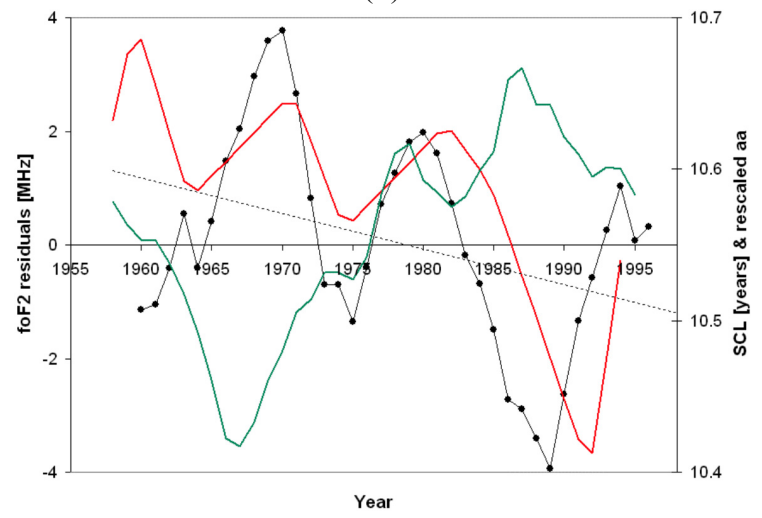

(c)

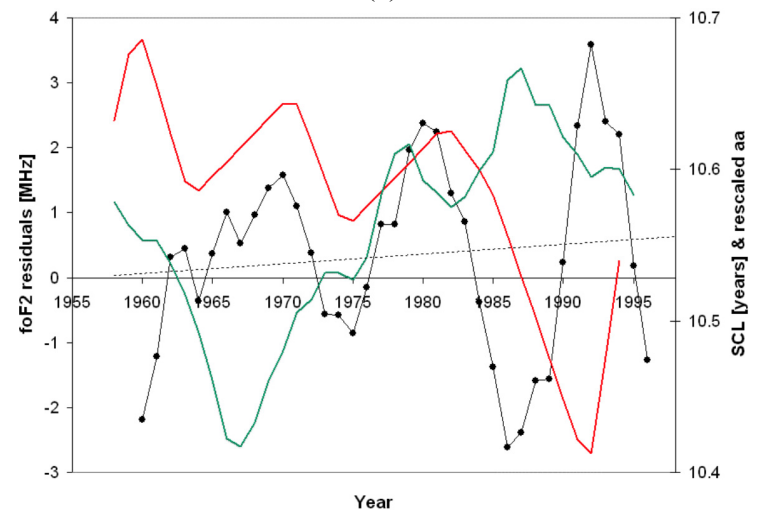

(d)

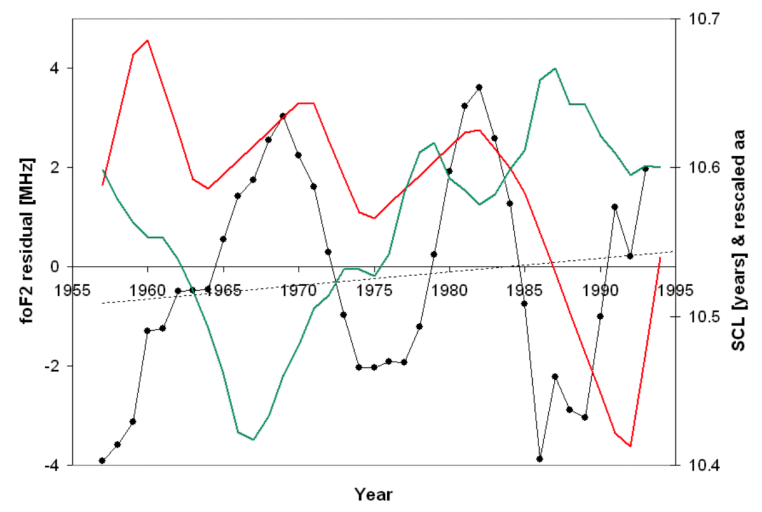

Fig. (2). SCL in years (red line), aa 11-year running mean (green line) rescaled to fit the SCL axis, foF 2 residuals (foF $\left.2_{\text {res }}\right)$ in $\mathrm{MHz}$ after a 5 year running mean (black line with filled circle), and foF $2_{\text {res }}$ linear trend (dotted line) for (a) Sodankyla $\left(67.4^{\circ} \mathrm{N}, 26.6^{\circ} \mathrm{E}\right),(\mathbf{b}) \mathrm{Uppsala}$ $\left(59.8^{\circ} \mathrm{N}, 17.6^{\circ} \mathrm{E}\right),(\mathbf{c})$ Moscow $\left(55.5^{\circ} \mathrm{N}, 37.3^{\circ} \mathrm{E}\right)$, and (d) Ottawa $\left(45.4^{\circ} \mathrm{N}, 284.1^{\circ} \mathrm{E}\right)$. 
Regarding the EUV long-term variation shown by SCL, an in-phase relation is apparent from Fig. (2), as shown by Adler et al. [1] for three other ionospheric stations. For Sodankyla and Uppsala, the correlation coefficient between foF $2_{\text {res }}$ and SCL is 0.52 and 0.56 respectively. However, for the other two stations, the correlation coefficient is only $\sim 0.15$.

In the case of geomagnetic activity, the expected anticorrelation is noticed from Fig. (2). The correlation coefficient between foF 2 res and aa 11-year running mean is 0.64 for Sodankyla and Uppsala, -0.45 for Ottawa, and -0.19 for Moscow. An explanation for the decrease of the correlation coefficient for decreasing latitudes may be that the strongest effects of geomagnetic storms are seen at higher latitudes.

\section{DISCUSSION AND CONCLUSIONS}

In this study, trends in the ionospheric parameter foF 2 are analyzed, through the study of foF $2_{\text {res }}$ which consists in the deviations of the real data from a model which takes into account only the changes described by Rz. Four liable factors, leading to deviations from the model and to longterm variations, are changes in solar EUV not properly presented by $\mathrm{Rz}$ variations, long-term changes of geomagnetic activity resulting in long-term trends of aeronomical parameters, increasing greenhouse gases concentration leading to a cooling at ionosphere heights, and secular variations of the Earth's main magnetic field.

$\mathrm{Rz}$, usually used in empirical ionospheric models, does not allow to completely eliminate the dependence of ionospheric parameters on solar activity. So it seemed reasonable to think of a remaining dependence on SCL as a proxy of solar activity variations not shown by Rz. However, from the cases here analyzed, any concluding remark was obtained regarding SCL. Probably the remaining effect of Rz on foF 2 masks other variation patterns. In fact, the filtering process here applied to foF2, do not completely remove the $\mathrm{Rz}$ effect, as can be seen in Fig. (3) which shows foF $2_{\text {res }}$ and the annual Rz. Some decadal variation linked to the solar cycle is still present in foF $2_{\text {res }}$.

Regarding geomagnetic activity, according to Mikhailov and Marin [4] and other papers by Mikahailov and Danilov $[3,5-8]$, periods with negative and positive foF2 trends correspond to the periods of increasing or decreasing geomagnetic activity with the turning points around 1955, and the end of the 1960s and 1980s, where foF2 change their trend signs. This behavior is seen in all the stations here analyzed (see Fig. 2). So, it can be concluded that geomagnetic activity trends do induce detectable trends in foF2. And the linear downward trend detected for two stations may be the result of the general increasing trend of aa.

With relation to greenhouse gases, many authors have estimated foF2 long-term trends for different ionospheric stations $[3,5,8,11-14]$. They found a variety of different values ranging from -0.029 to $0.017 \mathrm{Mhz} / \mathrm{year}$, and arrived to the conclusion that a change of greenhouse gases concentration is not sufficient to explain these different trends, which in addition are characterized by alternation of phases of decay and rise against the background of its general increase (or decrease). It seems that, in addition, the trend values depend on the estimation method, as stated by Jarvis et al. [46] and Lastovicka et al. [47]. From the data here analyzed, it can be said that Sodankyla and Uppsala, present foF2 decreasing trends in agreement, but much stronger, than trends expected from the greenhouse gases effect. Moscow and Ottawa do not present detectable trends, which does not contradicts the hypothesis of ionosphere trends induced by greenhouse gases. In fact, as already stated, the expected trends are really small and need much longer time series in order to be detected with a desirable statistical significance.

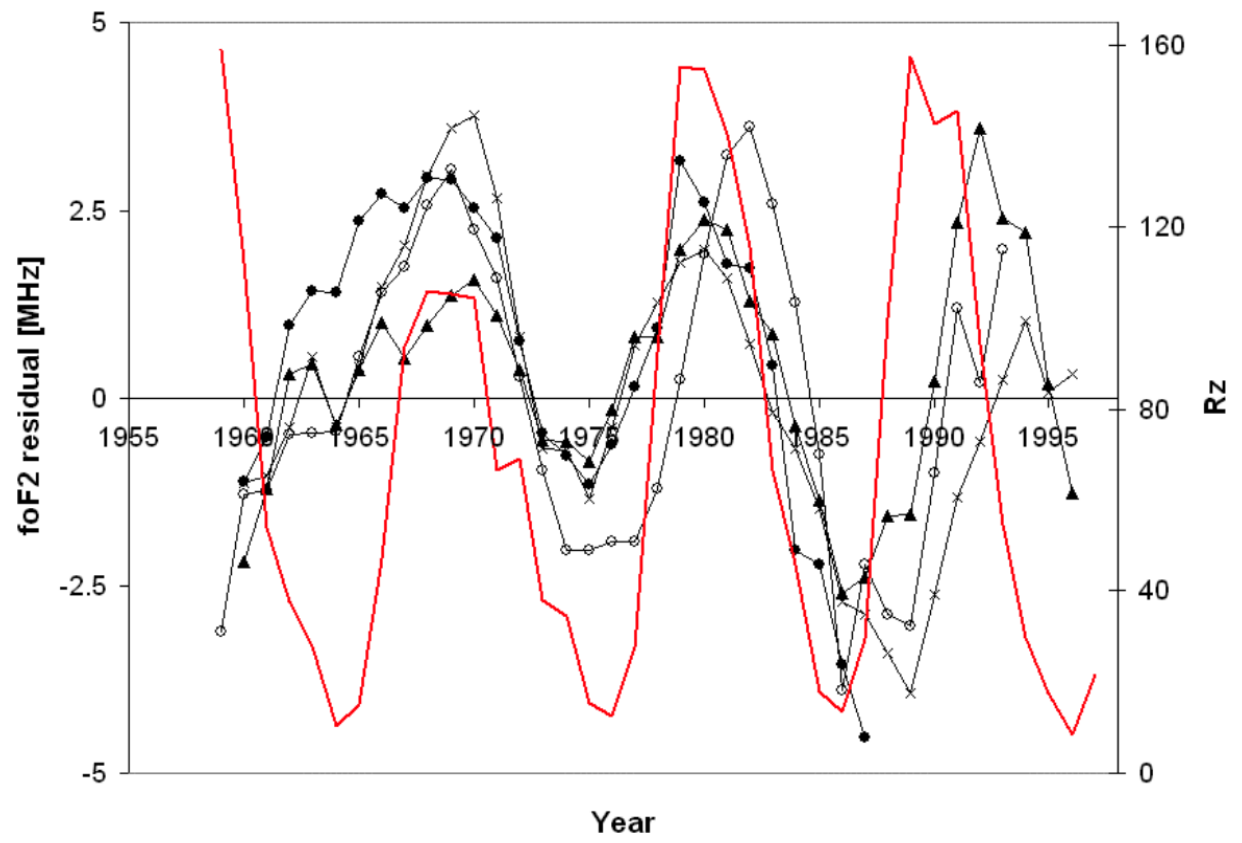

Fig. (3). foF 2 residuals (foF $2_{\text {res }}$ ) in MHz after a 5-year running mean for Sodankyla (filled circle), Uppsala (cross), Moscow (filled triangle), and Ottawa (empty circle), together with the annual sunspot number, Rz (red line). 
In conclusion, although the sources of long-term variations considered here are all capable of inducing ionospheric trends, any of them fully explain the observed trends in the experimental data considered. There might be other factors such as trends in thermospheric winds and neutral constituent variations affecting the ionosphere which were not considered. The subject of trends in the ionosphere is still under debate and there is not yet any agreement about the main mechanism responsible for the trends observed.

Why is it important to understand and measure the low, middle and upper atmosphere trends during the last decades? We live in the Earth and we want to understand and predict the atmosphere behavior which is essential for human life. And, in the present context, an understanding of the atmosphere variations is an essential focus of climate science, which is seeking to determine the extent to which human activities are altering the planetary energy balance through the emission of greenhouse gases and pollutants [48].

\section{ACKNOWLEDGEMENTS}

This research was performed under CONICET project PIP 114-200801-00470 and CIUNT project 26/E435.

\section{REFERENCES}

[1] Adler NO, Elias AG, Manzano JR. Solar cycle length variation: its relation with ionospheric parameters. J Atmos Solar Terr Phys 1997; 59: 159-62.

[2] Adler NO, Elías AG, Heredia T. Long-term changes in UV and EUV solar radiation. Geofisica Internacional 2000; 39: 93-5.

[3] Danilov AD, Mikhailov AV. Spatial and seasonal variations of the foF2 long-term trends. Ann Geophys 1999; 17: 1239-43.

[4] Mikhailov AV, Marin D. An interpretation of the foF2 and hmF2 long-term trends in the framework of the geomagnetic control concept. Ann Geophys 2001; 19: 733-48.

[5] Danilov AD, Mikhailov AV. F2-layer parameters long-term trends at the Argentine Islands and Port Stanley stations. Ann Geophys 2001; 19: 341-49.

[6] Mikhailov AV. The geomagnetic control concept of the F2-layer parameter long-term trends. Phys Chem Earth 2001; 27: 595-606.

[7] Mikhailov AV. Trends in the ionospheric E-region. Phys Chem Earth 2006; 31: 22-33.

[8] Danilov AD. Overview of the trends in the ionospheric E and F2 regions. Phys Chem Earth 2002; 27: 579-88.

[9] Bremer J. Ionospheric trends in mid-latitudes as a possible indicator of the atmospheric greenhouse effect. J Atmos Terr Phys 1992; 54: 1505-11.

[10] Bremer J. Trends in the ionospheric $\mathrm{E}$ and $\mathrm{F}$ regions over Europe. Ann Geophysicae 1998; 16: 986-96.

[11] Upadhyay HO, Mahajan KK. Atmospheric greenhouse effect and ionospheric trends. Geophys Res Lett 1998; 25: 3375-8.

[12] Ulich T, Turunen E. Evidence for long-term cooling of the upper atmosphere in ionosonde data. Geophys Res Lett 1997; 24: 11031106.

[13] Jarvis MJ, Jenkins B, Rodgers GA. Southern hemisphere observations of a long-term decrease in $\mathrm{F}$ region altitude and thermospheric wind providing possible evidence for global thermospheric cooling. J Geophys Res 1998; 103: 20774-87.

[14] Alfonsi L, de Franceschi G, Perrone L, Maerassi M. Long-term trends of critical frequency of the F2 layer at northern and southern high latitude regions. Phys Chem. Earth 2002; 27: 607-12.

[15] Foppiano AJ, Cid L, Jara V. Ionospheric long-term trends for South American mid-latitudes. J Atmos Solar Terr Phys 1999; 61: 71723.

[16] Elias AG, Adler NO. Earth magnetic field and geomagnetic activity effects on long term trends in the F2 layer at mid-high latitudes. J Atmos Solar Terr Phys 2006; 68: 1871-8.
[17] Elias AG. Trends in the F2 ionospheric layer due to long-term variations in the Earth's magnetic field. J Atmos Solar Terr Phys 2009; 71: 1602-9.

[18] Yue X, Liu L, Wan W, Wei Y, Ren Z. Modeling the effects of secular variation of geomagnetic filed orientation on the ionospheric long term trend over the past century. J Geophys Res 2008; 113: A10301.

[19] Cnossen I, Richmond AD. Modelling the effects of changes in the Earth's magnetic field from 1957 to 1997 on the ionospheric hmF2 and foF2 parameters. J Atmos Solar Terr Phys 2008; 70: 1512-24.

[20] Rao GMSV, Rao RS. The hysteresis variation in F2 layer parameters. J Atmos Terr Phys 1969; 31: 1119-25.

[21] Smith PA, King JW. Long-term relationship between sunspots solar faculae and the ionosphere. J Atmos Terr Phys 1981; 43: 1057-63.

[22] Adler NO, Ezquer RG, Manzano JR. On the relationship between ionospheric characteristics and solar indices. Adv Space Res 1993; 13: 75-8.

[23] Adler NO,. Manzano JR. Solar cycle hysteresis on F-region electron concentration peak heights over Tucuman. Adv Space Res 1995; 15: 83-8.

[24] Adler NO, Elias AG. Latitudinal variation of foF2 hysteresis of solar cycles 20, 21 and 22. Ann Geophysicae 2008; 26: 1269-73.

[25] Friis-Christensen E, Lassen K. Length of the solar cycle: An indicator of solar activity closely associated with climate. Science 1991; 254: 698-700.

[26] Lassen K, Friis-Christensen E. Variability of the solar cycle length during the past five centuries and the apparent association with terrestrial climate. J Atmos Solar Terr Phys 1995; 57: 835-45.

[27] Thejll P, Lassen K. Solar forcing of the Northern hemisphere land air temperature: New data. J Atmos Solar Terr Phys 2000; 62: 1207-13.

[28] Gleissberg W. A table of secular variations of the solar cycle. Terr Magneti Atmos Electricity 1944; 49: 243-4.

[29] Hoyt DV, Schatten KH. A discussion of plausible solar irradiance variations, 1700-1992. J Geophys Res 1993; 98: 18895-906.

[30] Mursula K, Ulich T. A new method to determine the solar cycle length. Geophys Res Lett 1998; 25: 1837-40.

[31] Fligge MS, Solanki K, Beer J. Determination of solar cycle length variations using the continuous wavelet transform. Astron Astrophys 1999; 346: 313-21.

[32] Prolss GW. On explaining the local time variation of ionospheric storm effects. Ann Geophysicae 1993; 11: 1-9.

[33] Rishbeth H. How the thermospheric circulation affects the ionospheric F2 layer. J Atmos Solar Terr Phys 1998; 60: 1385-402.

[34] Namgaladze AA, Förster M, Yurik RY. Analysis of the positive ionospheric response to a moderate geomagnetic storm using a global numerical model. Ann Geophysicae 2000; 18: 461-77.

[35] Buonsanto MJ. Ionospheric storms - A review. Space Sci Rev 1999; 88: 563-601.

[36] Tett SB, Stott PA, Allen MR, Ingram WJ, Mitchell JFB. Causes of twentieth-century temperature change near the Earth's surface. Nature 1999; 399: 569-72.

[37] IPCC, 2007: Climate Change 2007: Synthesis Report. Contribution of Working Groups I, II and III to the Fourth Assessment, Report of the Intergovernmental Panel on Climate Change [Core Writing Team, Pachauri, R.K and Reisinger, A. (eds.)]. IPCC, Geneva, Switzerland, $104 \mathrm{pp}$.

[38] Brasseur G, Hitchman MH. Stratospheric response to trace gas perturbations: Changes in ozone and temperature distribution. Science 1988; 240: 634-37.

[39] Roble RG, Dickinson RE. How will changes in carbon dioxide and methane modify the mean structure of the mesosphere and thermosphere? Geophys Res Lett 1989; 16: 1441-4.

[40] Rishbeth H A greenhouse effect in the ionosphere? Planet Space Sci 1990; 38: 945-48.

[41] Rishbeth H, Roble RG. Cooling of the upper atmosphere by enhanced greenhouse gases. Modeling of the thermospheric and ionospheric effects. Planet Space Sci 1992; 40: 1011-26.

[42] Bloxham J, Gubbins D. The secular variation of the Earth's magnetic field. Nature 1985; 317: 777-81.

[43] Hongre L, Hulot G, Khokhlov G. An analysis of the geomagnetic field over the past 2000 years. Phys Earth Planet Inter 1998; 106: 311-35.

[44] Rishbeth H. Thermospheric winds and the F-region: A review. J Atmos Solar Terr Phys 1972; 34: 1-47. 
[45] Rishbeth $\mathrm{H}$ and Garriott $\mathrm{OK}$. Introduction to ionospheric physics. New York, USA: Academic Press 1969; pp.331

[46] Jarvis MJ, Clilverd MA, Ulich T. Methodological influences on Fregion peak height trend analyses. Phys Chem Earth 2002; 27: 58994.
[47] Lastovicka J, Mikhailov AV, Ulich T, et al. Long-term trends in foF2: a comparison of various methods. J Atmos Solar Terr Phys 2006; 68: 1854-70.

[48] Elias AG, Lower and middle atmosphere and ozone layer responses to solar variation. Proceedings of the International Astronomical Union (2009), Cambridge University Press 2010; 5: pp. 336-42.

Received: July 8, 2010

Revised: July 19, 2010

Accepted: August 19, 2010

(C) Ana G. Elias; Licensee Bentham Open.

This is an open access article licensed under the terms of the Creative Commons Attribution Non-Commercial License (http: //creativecommons.org/licenses/by$\mathrm{nc} / 3.0 /$ ) which permits unrestricted, non-commercial use, distribution and reproduction in any medium, provided the work is properly cited. 